\title{
VAALVOTOMY IN MITRAL STENOSIS WITH EXTREME PULMONARY VASCULAR RESISTANCE
}

\author{
BY \\ RICHARD EMANUEL \\ From the Institute of Cardiology and National Heart Hospital and Brompton Hospital, London
}

Received June 21, 1962

Surgical treatment should be considered in all cases of mitral stenosis, and valvotomy is required if the stricture is sufficiently severe to cause symptoms. The risks and benefits of the operation vary considerably. For example, if mitral stenosis is the sole lesion and is uncomplicated by valve calcification, the operative mortality is between 1.5 and 3 per cent and the risk of an arterial embolism at the time of operation is between 5 and 8 per cent: an excellent or good symptomatic result is achieved in 75-80 per cent of these uncomplicated cases (Wood, 1956; 1961, personal communication). The risks increase considerably if, in the presence of dominant stenosis, the valve is calcified and incompetent. Under these circumstances the mortality and embolic risk at operation increase to 13 per cent while the prospect of an excellent or good result is only 50 per cent in the survivors (Wood, 1960, personal communication).

The present investigation was undertaken to determine the mortality, embolic risk, and ultimate fate of cases of mitral stenosis complicated by severe pulmonary hypertension due to extreme pulmonary vascular resistance (P.V.R.) which for the purposes of this work was taken as a minimum of 10 units (800 dynes sec. $/ \mathrm{cm}$.).

\section{SUBJECTS}

The study is based on 76 patients with mitral stenosis with P.V.R. of 10 units or over, who were operated on in the 11-year period 1950-1960. Seventy-three of these operations were carried out at the Brompton Hospital and 68 of the valvotomies $(90 \%)$ were performed by one of the following surgeons, Sir Russell Brock, Mr. Oswald Tubbs, and Mr. W. P. Cleland. The operative mortality and embolic risk at valvotomy have been calculated from the whole series of 76 cases. The rest of the analysis is based on 70 patients: 6 were excluded, as 4 lived overseas and it was impossible to obtain adequate information, and the remaining 2 were not traced. All other survivors were examined personally. Critical mitral stenosis (mitral orifice of $1.0 \times 0.5 \mathrm{~cm}$. or less) was common to all patients. In $39(51 \%)$ the valve was calcified and in 16 of these $(21 \%$ of the total) there was slight or moderate incompetence. An additional $5(7 \%)$ had slight to moderate mitral regurgitation without calcification.

Right heart catheterization was carried out before operation in 67 of the 76 and the P.V.R. ranged from 10-35 units with an average of 16.5 units. The average cardiac output was $2.91 . / \mathrm{min}$. The remaining 9 patients, all with signs of severe pulmonary hypertension, were considered too ill, or operation was too urgent, to warrant catheterization.

Operative Assessment. In each case the extent of the valvotomy was assessed at the time of operation. The surgeon recorded not only the final size of the mitral orifice but also the state of the commissures after division. The degree of valvotomy achieved was graded from this data as shown in Fig. 1. Effort intolerance was also graded: symptoms restricted to unusual activity, grade 1; symptoms walking at a normal pace, grade 2; symptoms unavoidable on walking even at a slow pace, grade 3; total incapacity, grade 4. The post-operative results were classed as "good" when residual disability was minimal or absent or when the post-operative effort intolerance had improved by two grades or more. 


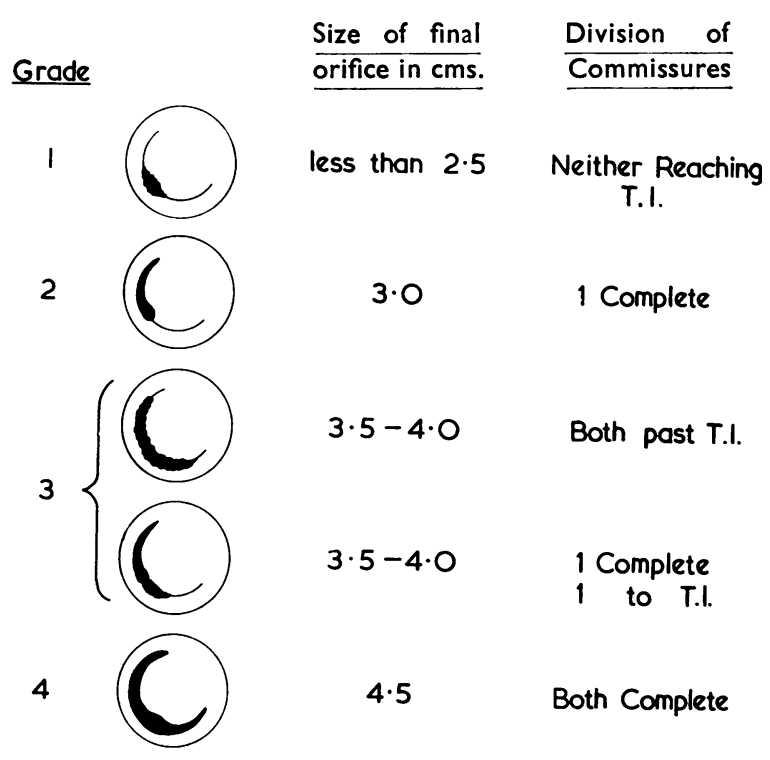

FIG. 1.-Grades of valvotomy derived from the surgeon's description of the size of the valve orifice and the state of the commissure after operation.

T.I. = Critical areas of tendon insertion (Brock, 1952).

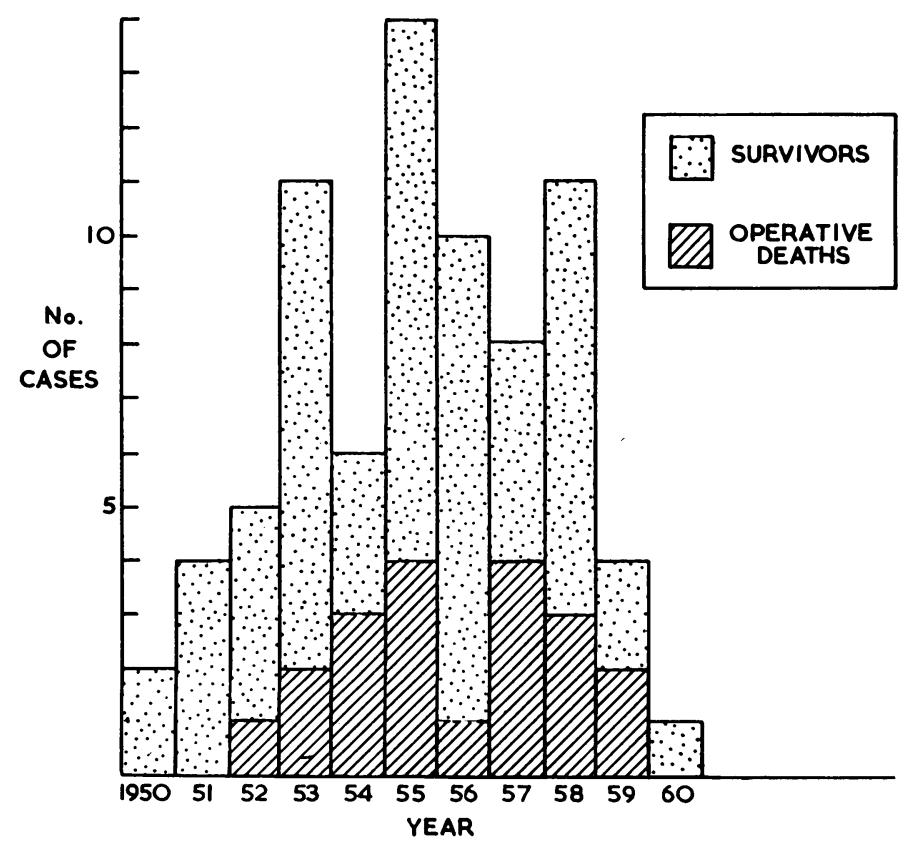

FIG. 2.-The operative mortality per annum in 76 cases of mitral stenosis complicated by extreme P.V.R. operated on between 1950 and 1960.

\section{RESULTS}

Operative Mortality (76 cases). Operative mortality includes death within 8 weeks of operation, that is patients who failed to leave hospital alive after mitral valvotomy. Fig. 2 shows the number of operations carried out each year and the operative mortality. There were 20 deaths within 8 weeks of the operation, a mortality of 26 per cent. Thirteen of these deaths occurred within 24 hours of operation. A more detailed analysis of the mortality is given in Table I and shows that when extreme P.V.R. was the only complicating factor the operative mortality was 13 per cent, the presence of valve calcification doubled the risk $(26 \%)$, and the presence of both calcification and slight to moderate mitral regurgitation almost quadrupled the original figure $(50 \%)$.

The method of valvotomy, whether transatrial and carried out with the finger and knife or transventricular, appeared to make little difference to the mortality. There were 61 transatrial operations with 16 deaths, a mortality of 26 per cent compared with 15 transventricular operations and 4 deaths, a mortality of 27 per cent. There are, however, too few transventricular operations to draw any conclusions from these figures. The cause of death in these 20 cases is shown in Table II.

Systemic Emboli During Operation (76 cases). Eight patients $(11 \%)$ developed systemic emboli during the operation. In 4 instances the embolus was fatal (3 cerebral and 1 coronary) and in the 4 non-fatal cases all had saddle emboli: one of these patients, in addition, had a simultaneous 
TABLE I

Operative Mortality in Cases of Mitral Stenosis with Extreme P.V.R. Related to Presence or Absence of Valve Calcification and Slight to Moderate Mitral Regurgitation

\begin{tabular}{|c|c|c|c|}
\hline & No. of cases & $\begin{array}{c}\text { Operative } \\
\text { deaths }\end{array}$ & $\begin{array}{c}\text { Operative }(\%) \\
\text { mortality }\end{array}$ \\
\hline $\begin{array}{l}\text { M.S.+extreme P.V.R. [No. Ca., no M.R.] } \\
\text { Calcific M.S.+ extreme P.V.R. [No. M.R.] } \\
\text { M.S + M.R. + extreme P.V.R. [No. Ca.] } \\
\text { Calcified M.S.+M.R. +extreme P.V.R. }\end{array}$ & $\begin{array}{r}32 \\
23 \\
5 \\
16\end{array}$ & $\begin{array}{l}4 \\
6 \\
2 \\
8\end{array}$ & $\begin{array}{l}13 \\
26 \\
40 \\
50\end{array}$ \\
\hline Total & 76 & 20 & 26 \\
\hline
\end{tabular}

TABLE II

Cause of Death in 20 Cases Dying within 8 Weeks of Valvotomy

Operative Mortality

\begin{tabular}{|c|c|c|}
\hline Cause & & No. of Cases \\
\hline $\begin{array}{ll}\text { Emboli * .. } & \ldots \\
\text { Mitral regurgitation } \\
\text { Unrelieved M.S. } \\
\text { Hæmorrhage } & \ldots \\
\text { Unrelieved P.H. } & \ldots \\
\text { Other causes } & . \\
\end{array}$ & $\begin{array}{l}. . \\
\therefore \\
\therefore \\
\therefore \\
.\end{array}$ & $\begin{array}{l}6 \\
5 \\
3 \\
2 \\
1 \\
3\end{array}$ \\
\hline Total & & 20 \\
\hline
\end{tabular}

* Cerebral 3; pulmonary 2 ; coronary 1 .

cerebral embolus. The presence of mitral valve calcification did not alter the embolic risk, which was 10 per cent in the calcific cases and 11 per cent in those free from calcium. Half the emboli (4) occurred after a grade 4 valvotomy: of the remainder, 2 occurred after a grade 3 valvotomy and 2 after a grade 2 valvotomy. It appears, therefore, that the more complete the valvotomy the greater the risk of an embolus at the time of operation. The reason for this is not apparent and it is quite possible that this relation is fictitious owing to the small numbers involved.

Symptomatic Results (50 cases). Forty-two of the 50 survivors $(84 \%)$ were totally or severely disabled (effort intolerance grade 3 or grade 4) before operation. Symptomatic improvement depended on the degree to which the stenosis was relieved and the absence of complications such as mitral regurgitation and emboli. Twelve patients $(24 \%)$ had a complete valvotomy, grade $4 ; 16$ $(32 \%)$ a grade 3 valvotomy; a further $12(24 \%)$ a grade 2 valvotomy; and $10(20 \%)$ a grade 1 valvotomy. A final mitral orifice of $3 \mathrm{~cm}$. or complete division of one commissure (grade 2 valvotomy) was sufficient to produce a "good" symptomatic result in 50-58 per cent of cases. Fig. 3 shows that a more complete valvotomy did not increase the percentage of "good" results.

Pulmonary Arterial Pressure Response to Acetylcholine. The effect of acetylcholine on the pulmonary arterial pressure was examined in 18 cases before operation using the technique described by Wood et al. (1957). Subsequently 14 of these had an adequate valvotomy (grade 2 or better). Table III relates the pre-operative response to acetylcholine to the post-operative fall in P.V.R. in these 14 cases. In 7 the pulmonary artery systolic pressure fell $15 \mathrm{~mm}$. $\mathrm{Hg}$ or more (average fall $27 \mathrm{~mm} . \mathrm{Hg}$, range 15 to $50 \mathrm{~mm} . \mathrm{Hg}$ ) and in all these the P.V.R. returned to normal after valvotomy. In 3 cases the fall in pulmonary artery pressure was only moderate $(5$ to $14 \mathrm{~mm}$. $\mathrm{Hg}$ ): 2 of these did well but the third died two years after valvotomy (grade 3) from unrelieved pulmonary hypertension. 


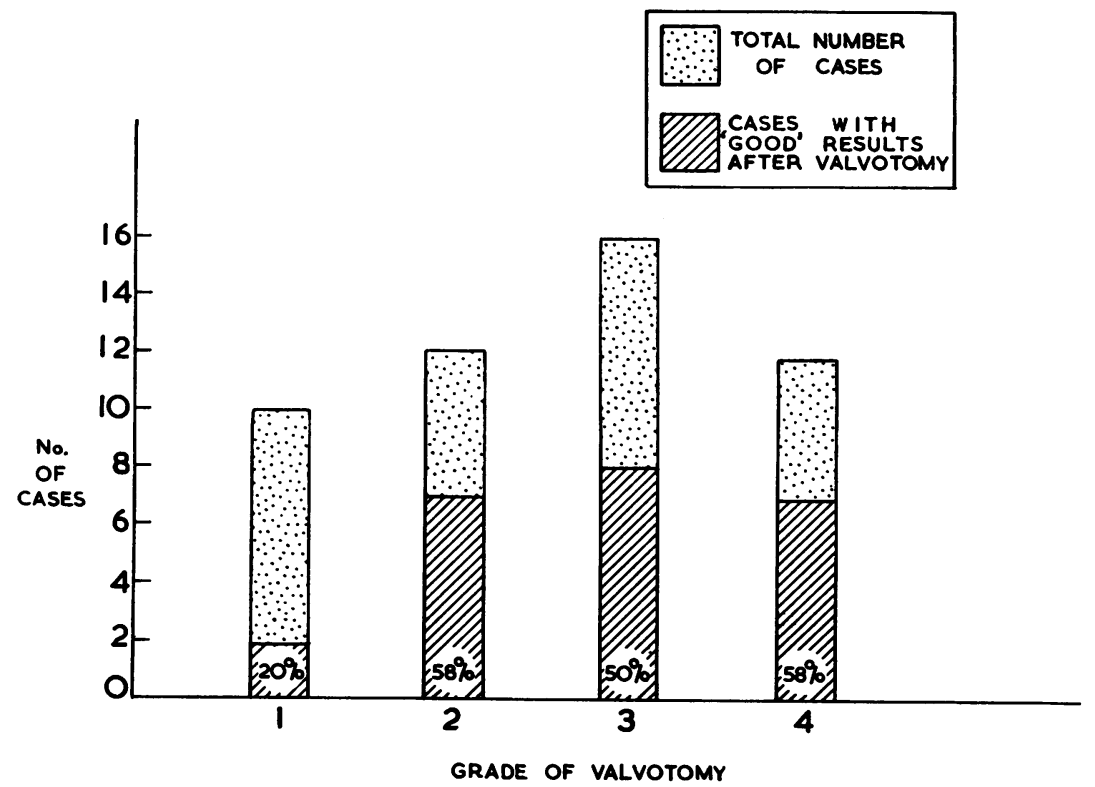

Fig. 3.-The symptomatic results of mitral valvotomy related to the relief of stenosis obtained. Results were classed as "good" when residual disability was minimal or absent or when the post-operative effort intolerance had improved by two grades or more.

Four cases failed to respond to acetylcholine, in 2 of these the P.V.R. was much improved if not normal following valvotomy: the remaining 2 , however, died of unrelieved pulmonary hypertension one week and four months after an adequate valvotomy (grade 2 and 3 respectively).

Later Mortality in the Post-operative Survivors (50 cases). Fifty of the 56 patients who survived operation were followed up from 1 to 10 years after valvotomy with an average of 5.4 years. During this time a further 7 have died ( 3 months, 7 months, 2 years, 3 years, and the other three in the sixth year after valvotomy) all from cardiac failure. Five of these had an inadequate mitral valvotomy (grade 1). The remaining 2 patients died from unrelieved pulmonary hypertension, in spite of a good valvotomy (both grade 3). In one of these the pre-operative response to acetylcholine was negative $(4 \mathrm{~mm}$. $\mathrm{Hg})$, and in the other moderate, $13 \mathrm{~mm} . \mathrm{Hg}$.

Post-operative Mitral Regurgitation. Post-operative mitral regurgitation was the immediate cause of death in 5 of the 20 patients who died within eight weeks of valvotomy, and it was a significant factor in 4 of the 7 late deaths. Twenty-two of the 50 patients who survived operation developed mitral regurgitation or pre-existing regurgitation increased: in 7 of these cases the regurgitation was considerable and in the remaining 15 slight to moderate.

TABLE III

Fall in Pulmonary Arterial Systolic Pressure following Injection of ACETYlCholine Related to Fall in P.V.R. AFter Valvotomy

\begin{tabular}{c|c|c|c}
\hline $\begin{array}{c}\text { Fall in P.A. } \\
\text { systolic } \\
\text { pressure } \\
\text { (mm. Hg) }\end{array}$ & No. of cases & $\begin{array}{c}\text { Fall in P.V.R. } \\
\text { after } \\
\text { valvotomy }\end{array}$ & $\begin{array}{c}\text { Deaths from } \\
\text { unrelieved } \\
\text { pulmonary } \\
\text { hypertension }\end{array}$ \\
\hline$>15$ & 7 & 7 & 0 \\
$5-14$ & 3 & 2 & 1 \\
$0-4$ & 4 & 2 & 2 \\
\hline
\end{tabular}


Post-operative regurgitation was unrelated to the degree of valvotomy achieved. The symptomatic results were uninfluenced unless the regurgitation was sufficient to maintain a high left atrial pressure which probably prevented the P.V.R. from falling. Calcification of the valve, however, was frequently associated with post-operative incompetence. It occurred in 4 of the 5 operative deaths, 2 of the 4 late deaths, and in 11 of the 22 survivors.

P.V.R. after Valvotomy. The post-operative P.V.R. was measured at cardiac catheterization in 13 cases at varying intervals after valvotomy. In the remainder it was estimated clinically, electrocardiographically, and radiologically and was not accepted as, or near, normal unless the right ventricular impulse, venous pulse, and pulmonary component of the second heart sound were normal. In addition either electrocardiographic evidence of regression of the right ventricular hypertrophy was required or a reduction in heart size radiologically. Using these criteria the P.V.R. fell to, or near, normal in 31 cases, and remained extreme or considerably elevated in 19. In 10 of these the valvotomy (grade 1) was inadequate to relieve the stenosis; and in a further 7 considerable incompetence was created at operation, sufficient to maintain an elevated left atrial pressure and so prevent a fall in resistance. In the remaining 2 cases the P.V.R. failed to fall in spite of a good valvotomy (both grade 3 ) and absence of post-operative mitral incompetence.

Re-stenosis. Excluding all cases where the original valvotomy was inadequate (grade 1) re-stenosis occurred in 6 cases which is 2.4 per cent per annum. This figure is the same as in mitral stenosis with a normal P.V.R. (Wood, 1954). No case re-stenosed following a complete valvotomy (grade 4). Four cases re-stenosed after a grade 3 valvotomy, and the remaining 2 after a grade 2 valvotomy. The present analysis failed to show any special factors predisposing to re-stenosis.

\section{Discussion}

In cases of critical mitral stenosis with extreme P.V.R. the operative mortality varied from 13 per cent in uncalcified cases to 50 per cent in cases complicated by valve calcification and slight to moderate mitral regurgitation. This high mortality was primarily due to the severity of the preoperative condition and the residual obstruction in the lungs which persists for many months in these cases even after successful valvotomy. These factors combine to increase the hazards of operation and the immediate post-operative period, so that relatively minor degrees of hæmorrhage and hypoxia or increase in the degree of mitral regurgitation readily prove fatal.

At operation systemic emboli occurred in 11 per cent, which compared not unfavourably with 5 to 8 per cent in cases with normal P.V.R. operated on during the same period and by the same group of surgeons. In cases with extreme P.V.R., however, there was an additional thromboembolic hazard from pulmonary embolism and thrombosis, which frequently occurred before operation while the patient was immobilized in hospital awaiting cardiac catheterization or valvotomy. This problem, and its prevention with anticoagulants, has been discussed elsewhere (Emanuel, 1961).

Symptomatic relief was obtained in 50-58 per cent of all cases in which the final mitral orifice was $3.0 \mathrm{~cm}$. or where one commissure had been divided completely. If the valvotomy was more complete the percentage of good results did not increase, mainly because operative emboli, with their ensuing disability, occurred more frequently with more extensive valvotomies. The more complete the relief of the stenosis, however, the more likely was the P.V.R. to return to normal (Fig. 4), although in 3 cases $(4 \%)$ the P.V.R. appeared "fixed", in that it remained extreme, even after an adequate valvotomy uncomplicated by mitral regurgitation. It appears, therefore, that in addition to the vasoconstrictive factor (Wood, 1958) irreversible organic changes occur in the pulmonary arterioles in a small number of cases.

Wood's demonstration of a vasoconstrictive factor in most cases of mitral stenosis with extreme P.V.R. suggested that the response of the pulmonary arterial pressure to acetylcholine might be a useful method in predicting the post-operative behaviour of the P.V.R. after successful valvotomy. Observations on 14 cases showed that if there was a fall in the pulmonary arterial systolic pressure of $15 \mathrm{~mm}$. $\mathrm{Hg}$ or more and this was followed by an adequate valvotomy (grade 2 or better), then 


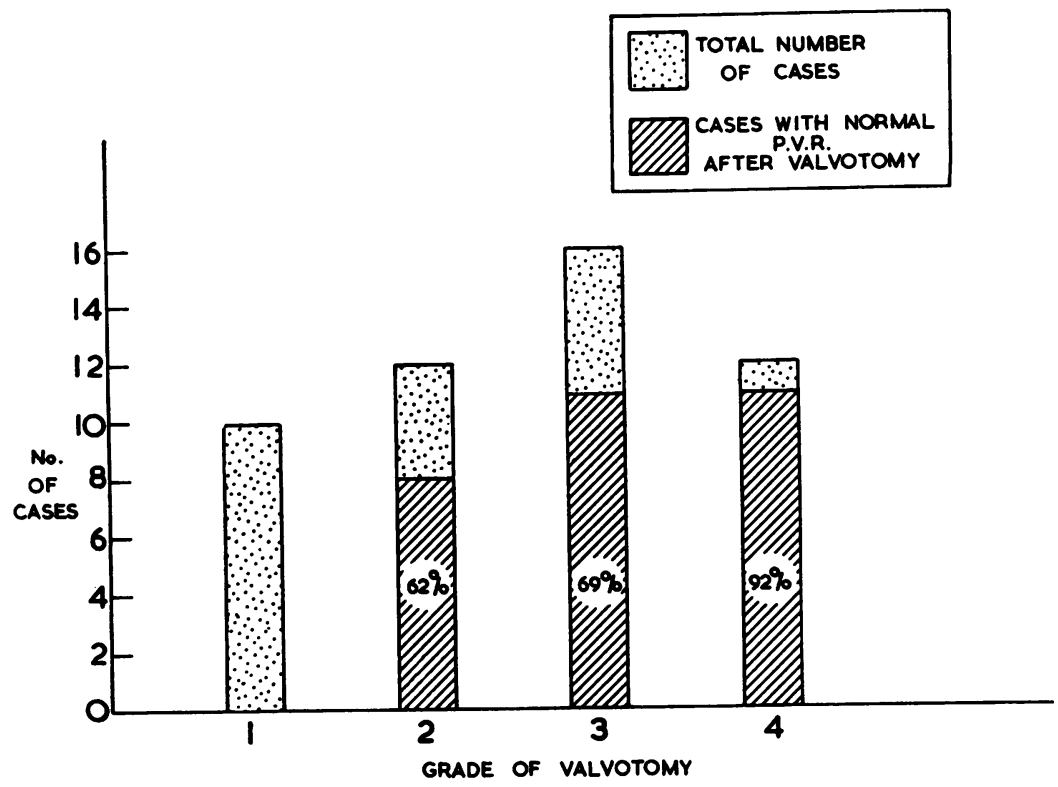

FIG. 4.-The fall in P.V.R. related to the relief of stenosis obtained.

the P.V.R. could be expected to return to normal. If, however, the fall in pulmonary arterial pressure was less than $15 \mathrm{~mm}$. $\mathrm{Hg}$ the prognosis should be guarded as a proportion of these cases would die from cardiac failure due to unrelieved pulmonary hypertension, in spite of an adequate valvotomy.

\section{SUMMARY}

In 76 cases of mitral stenosis complicated by extreme P.V.R. (over 10 units) the operative mortality was 26 per cent. If extreme P.V.R. was the only complicating factor the mortality was 13 per cent. The presence of mitral valve calcification increased the operative mortality to 26 per cent and the presence of both calcification and slight to moderate mitral regurgitation increased the mortality to 50 per cent. Systemic emboli occurred at operation in 11 per cent of cases and were fatal in 50 per cent. Half the emboli occurred in association with a complete valvotomy (grade 4). Mitral valve calcification did not increase the risk of an operative embolus. A final opening of $3 \mathrm{~cm}$. or complete division of one commissure (grade 2 valvotomy) was adequate to give a "good" symptomatic result in 50-58 per cent of cases. A more complete valvotomy did not increase the percentage of "good" results. The more complete the valvotomy the more likely was the P.V.R. to return to normal. Factors preventing the P.V.R. returning to normal were inadequate valvotomy, post-operative mitral regurgitation, and occasionally "fixed" pulmonary hypertension. Restenosis occurred at the rate of 2.4 per cent per annum. If, after injection of acetylcholine into the pulmonary artery, there was a fall of $15 \mathrm{~mm}$. $\mathrm{Hg}$ or more in the pulmonary arterial systolic pressure, it could be predicted that the P.V.R. would return to normal following an adequate valvotomy. If, after injection of acetylcholine into the pulmonary artery there was a negative or submaximal response $(14 \mathrm{~mm}$. $\mathrm{Hg}$ or less) there was a possibility that the P.V.R. had become "fixed".

All the cases studied were under the care of Dr. Paul Wood, and approximately one-third of them were originally reported in "An Appreciation of Mitral Stenosis" (Wood, 1954).

I am most grateful to Dr. Wood for his help which has been readily available throughout this work, and to the following surgeons for permission to report their operative findings: Sir Russell Brock (47 cases), Mr. O. S. Tubbs (11 cases), Mr. W. P. Cleland (10 cases), Mr. N. R. Barrett (3 cases), Mr. M. Paneth (2 cases), Mr. G. C. Laurie Pile ( 2 cases), and Professor R. S. Pilcher (1 case). 


\section{REFERENCES}

Brock, R. C. (1952). Brit. Heart J., 14, 489.

Emanuel, R. W. (1961). In Symposium on Anticoagulant Therapy, Report on the Proceedings, ed. G. W. Pickering, p. 271. Harvey and Blythe, London.

Wood, P. (1954). Brit. med. J., 1, 1051.

(1956). Diseases of the Heart and Circulation, 2nd ed. Eyre and Spottiswoode, London.

- (1958). Brit. Heart J., 20, 557. Besterman, E. M., Towers, M. K., and Mcllroy, M. B. (1957). Brit Heart J., 19, 279. 